\title{
GÊNERO REPORTAGEM OU GÊNEROS REPORTAGEM?
}

Cássio Florêncio Rubio

Doutorando em Estudos Linguísticos no Instituto de Biociências, Letras e Ciências Exatas - Ibilce, da Universidade Estadual Paulista - UNESP.

\section{RESUMO}

Considerando as inúmeras pesquisas a respeito do gênero textual (MARCUSCHI, 2008, 2009; BONINI, 2003; BRONCKART, 1999; BAZERMAN, 2006a, 2006b), pretendemos, neste trabalho, analisar duas reportagens jornalísticas de uma revista semanal, buscando evidenciar as características que podem assemelhar e diferenciar produções textuais inseridas em um mesmo contexto cultural e social e em um mesmo suporte de gênero. Para tanto consideraremos os textos sob a perspectiva textual-interativa (MARCUSCHI, 2008), procurando demonstrar que, apesar de aparentemente se inserirem em um mesmo gênero, podem ser estruturados de forma diferente, por vezes, assumindo formatos assemelhados aos de outros gêneros textuais. O córpus analisado compõe-se de duas reportagens da Revista Época, do mês de agosto de 2008, pertencentes à coluna Saúde \& Bem-Estar.

PALAVRAS-CHAVE: gênero textual; perspectiva textual-interativa; reportagem.

\begin{abstract}
Considering the countless researches regarding the textual gender (MARCUSCHI, 2008, 2009; BONINI, 2003; BRONCKART, 1999; BAZERMAN, 2006a, 2006b), we intended, in this work, to analyze two journalistic reports of a weekly magazine, looking for to evidence the characteristics that can assimilate and to differentiate textual productions inserted in a same cultural and social context and in a same gender support. For so much we will consider the texts in the textual-interactive perspective (MARCUSCHI, 2008), trying to demonstrate that, in spite of seemingly if they insert in a same gender, they can be structured in a different way, per times, assuming formats assimilated to the of other textual genders. The córpus analyzed is composed of two reports of the Revista Época, of the month of August of 2008, belonging to the column Saúde \& Bem-estar.
\end{abstract}

KEYWORDS: textual gender; textual-interactive perspective; report.

\section{Pressupostos teóricos}

Não existe um uso significativo da língua fora das inter-relações pessoais e sociais situadas. [...] Isto quer dizer que todo uso autêntico da língua é feito em textos produzidos por sujeitos históricos e sociais de carne e osso, que mantêm algum tipo de relação entre si e visam a algum objetivo comum.

LUIZ ANTÔNIO MARCUSCHI [i]

A linguagem humana é uma forma de produção interativa associada às atividades sociais, considerada um instrumento pelo qual os interactantes podem emitir presunções relativas às propriedades do contexto em que essa atividade se desenvolve. A linguagem é uma característica comum à atividade social humana, que possui como função primordial a ordem comunicativa ou pragmática (BRONCKART, 1999). A estabilização dos signos se faz por meio do confronto do valor ilocucionário das produções compartilhadas (convencionais). Essa semiotização permite o nascimento de uma atividade da linguagem que se organiza em discursos ou textos. "Sob o efeito da diversificação das atividades não verbais com as quais esses textos estão em interação, eles mesmos diversificam-se em gêneros" (BRONCKART, 1999, p. 36).

Uma comunidade verbal constitui-se de inúmeras formações sociais, que, em função de seus objetivos e interesses particulares, elaboram modalidades particulares de funcionamento da língua, chamadas por Foucault apud Bronckart (1999, p. 37) de formações discursivas. Essas formações são mecanismos que, ao mesmo tempo que geram modalidades particulares de organização dos signos e chegam a formas variadas de discurso (gêneros textuais, segundo Bronckart), moldam os conhecimentos dos membros de uma mesma formação social, de uma forma própria.

Dessa análise, destacam-se duas consequências importantes. A primeira diz respeito ao fato de que toda a língua possui um conjunto de subsistemas encaixados e movediços, que são apreensões abstratas das modalidades de funcionamento dos vários gêneros de textos. A segunda consequência é que os mundos representados, apesar de condicionados pela semântica global da língua natural utilizada, são também influenciados e marcados pelas semanticizações particulares induzidas pelos gêneros de textos em uso.

Ainda que se mantenha uma abordagem sincrônica da língua, as produções verbais efetivas assumem aspectos diversos, principalmente por serem articuladas em situações diferentes de comunicação. Essas formas de realização empíricas diversas são chamadas de textos (BRONCKART, 1999).

Segundo Marcuschi (2009), os gêneros textuais são fenômenos históricos que se relacionam diretamente ao cotidiano social e cultural das pessoas que o utilizam. São necessários para a realização de atividades do dia-a-dia, possuindo alto teor de predição, o que não faz, contudo, que sejam um fenômeno estanque, estável, imutável. Pelo contrário, são "maleáveis, dinâmicos e plásticos".

\subsection{A distinção entre texto, discurso e gênero}

Conforme afirma Marcuschi (2008, p. 81-82), "não é interessante distinguir rigidamente entre texto e discurso, 
pois a tendência atual é ver um contínuo entre ambos com uma espécie de condicionamento mútuo". Da mesma forma, afirma o autor, o gênero não é algo diverso, pois “é aquele que condiciona a atividade comunicativa”.

Para Maingueneau apud Adam (1990, p. 40):

Ao falarmos de discurso articulamos o enunciado sobre uma situação de enunciação singular; ao falar de texto, colocamos o acento sobre aquilo que lhe confere uma unidade, que o torna uma totalidade e não um simples conjunto de frases.

Coutinho apud Marcuschi (2008, p. 84) propõe o seguinte esquema para dar conta do texto como objeto empírico:

\begin{tabular}{|c|c|}
\hline $\begin{array}{c}\text { Discurso } \\
\text { (objeto do dizer) }\end{array}$ & $\begin{array}{c}\text { Texto } \\
\text { (objeto da figura) }\end{array}$ \\
TEXTO (objeto empírico) & Gênero \\
\hline
\end{tabular}

O discurso (objeto do dizer) deve ser considerado sempre como uma associação entre uma codificação linguística, uma prática social e um contexto histórico no qual a atividade se insere. Há a influência constante dos participantes nessa enunciação, que se inserem em uma situação sócio-histórica. O uso da língua no plano discursivo não deve ser encarado como uma codificação e decodificação, pois os aspectos pragmáticos, tipológicos, os processos de esquematização e os elementos relativos ao gênero também devem ser considerados.

O texto (objeto de figura) não deve ser considerado simplesmente como uma ordenação de enunciados, mas em sua configuração global. Nas palavras de Marcuschi (2008, p. 84), “o texto é o observável, o fenômeno linguístico empírico que apresenta todos os elementos configuracionais que dão acesso aos demais aspectos da análise".

O gênero se situa entre o discurso e o texto, considerado uma prática social e textual-discursiva, sendo considerado o elo entre o discurso e o texto, sendo, o primeiro, mais universal e o segundo, empírico e observável. Na visão de Coutinho apud Marcuschi (2008, p. 84-85):

Gêneros são modelos correspondentes a formas sociais reconhecíveis nas situações de comunicação em
que ocorrem. Sua estabilidade é relativa ao momento histórico-social em que surge e circula. [...] O
gênero prefigura o texto e o gênero define o que no texto empírico faz a figura do texto.

Segundo Marcuschi (2008, p. 85), “o gênero é uma escolha que leva consigo uma série de consequências formais e funcionais". Ou seja, para o autor, ao realizarmos nossas atividades diárias, temos que abrir mão de um discurso característico, que deve se iniciar com a escolha de um gênero, que possui por sua vez uma esquematização textual.

Para ilustrar a afirmação acima, pode-se imaginar uma empresa qualquer de venda de produtos que quer anunciar seus artigos em um jornal impresso de notícias diário. A intenção da empresa é, obviamente, obter como resultado o aumento nas vendas de seus produtos. Porém, para que seja obtido o resultado esperado, o anúncio deve atingir seus leitores de forma plena, o que somente será possível se observadas questões de ordem social, histórica e contextual, tais como:

- $\quad$ quais informações são extremamente relevantes (nome da empresa, produtos anunciados, preços, endereço da empresa - seja ele virtual ou físico);

- quais as formas de pagamento;

- qual o prazo de validade do anúncio;

- qual o formato do anúncio (que espaço será disponibilizado no meio impresso);

- quais as características sociais dos possíveis clientes da empresa (essas características se assemelham às características dos leitores do jornal?);

- qual a situação monetária do país (essa consideração pode ser usada positivamente no anúncio);

- qual linguagem deve ser utilizada no anúncio.

É possível notar que inúmeras outras questões poderiam ser consideradas, visto qualquer discurso estar inserido em uma realidade social e histórica. Assim, a decisão de persuasão por meio do discurso deve passar pela decisão do uso de um gênero, que funciona como uma escolha dos elementos linguísticos e extralinguísticos do texto e, além disso, principalmente, com a consideração tanto do contexto social, quanto do contexto histórico. A materialização do discurso é feita por meio do texto, que passa por um filtro histórico, social e contextual, imposto pelo gênero. O gênero se constrói pelas relações entre os outros textos e também pelo contexto em que se inserem os indivíduos.

\subsection{Gênero textual versus tipo textual}

É importante também a distinção entre gêneros textuais e tipos textuais, já que, em alguns momentos, as definições se confundem. Reproduzimos aqui a definição das duas noções, expostas por Marcuschi (2009) e 
a) Usamos a expressão tipo textual para designar uma espécie de construção teórica definida pela natureza lingüística de sua composição \{aspectos lexicais, sintáticos, tempos verbais, relações lógicas\}. Em geral, os tipos textuais abrangem cerca de meia dúzia de categorias conhecidas como: narração, argumentação, exposição, descrição, injunção.

b) Usamos a expressão gênero textual como uma noção propositalmente vaga para referir os textos materializados que encontramos em nossa vida diária e que apresentam características sóciocomunicativas definidas por conteúdos, propriedades funcionais, estilo e composição característica. Se os tipos textuais são apenas meia dúzia, os gêneros são inúmeros. Alguns exemplos de gêneros textuais seriam: telefonema, sermão, carta comercial, carta pessoal, romance, bilhete, reportagem jornalística, aula expositiva, reunião de condomínio, notícia jornalística, horóscopo, receita culinária, bula de remédio, lista de compras, cardápio de restaurante, instruções de uso, outdoor, inquérito policial, resenha, edital de concurso, piada, conversação espontânea, conferência, carta eletrônica, bate-papo por computador, aulas virtuais e assim por diante.

(MARCUSCHI, 2009, p. 5)

Pode-se notar que a definição de tipo textual está ligada às sequências linguísticas empregadas, responsáveis por nortearem a produção. Já a definição de gênero textual liga-se à prática da produção, às questões históricas, às questões particulares que envolvem essa produção, ou seja, todas as influências externas e as crenças do próprio produtor, que irão direcionar a caracterização do texto. Para encerrar, podemos notar em um mesmo gênero textual, como uma carta pessoal, mais de um tipo textual, pois um mesmo texto desse gênero pode conter trechos do tipo descritivo, narrativo, argumentativo, expositivo etc.

\subsection{O suporte de gênero ou hipergênero}

Para Marcuschi (2003), todo gênero textual possui um suporte, que seria o meio pelo qual o gênero pode circular na sociedade. Nos dizeres do autor:

Intuitivamente, entendemos aqui como suporte de um gênero um locus físico ou virtual com formato específico que serve de base ou ambiente de fixação do gênero materializado como texto. Numa definição sumária, pode-se dizer que suporte de um gênero é uma superfície física em formato específico que suporta, fixa e mostra um texto.

(MARCUSCHI, 2003, p. 8)

Um suporte pode trazer em seu interior inúmeros gêneros diferentes. É possível observar em uma revista semanal ou em um jornal impresso diário artigos de opinião, reportagens jornalísticas, narrativas, informes publicitários etc. O suporte pode influenciar nas características estruturais desses gêneros, visto cada suporte possuir particularidades e estar inserido em contextos sociais diferentes. A publicidade veiculada em revistas masculinas como Playboy e Sexy provavelmente não se assemelha à publicidade veiculada em revistas de notícias e reportagens semanais como Época e Veja. Um mesmo produto é anunciado de forma diferente nesses suportes e, provavelmente, será anunciado de outra forma em um jornal impresso diário. O suporte pode então ocasionar alterações tanto de formato quanto de função do gênero.

Para Bonini (2003), os meios de circulação dos diversos gêneros em sociedade podem ser classificados como hipergêneros, que são gêneros que se compõem de outros gêneros. Aparentemente, não há diferenciação, a não ser terminológica, entre o suporte (MARCUSCHI, 2003) e o hipergênero (BONINI (2003). Assim como o suporte, o hipergênero tem papel determinante nas características evidenciadas pelos gêneros que o compõem.

O gênero não pode ser estudado isoladamente, pois, além das questões sociais e culturais envolvidas no ato comunicativo, é determinante levar em consideração o suporte ou hipergênero do qual ele faz parte.

\subsection{A mescla de gêneros}

Como já foi possível notar, os gêneros textuais não possuem formas estáticas e determinadas. Na verdade, como afirma Marcuschi (2009, p. 10), "os gêneros são muito mais famílias de textos com uma série de semelhanças". É impossível definir quantos e quais são os gêneros existentes, pois não é possível definir um gênero por propriedades necessárias e indispensáveis. A presença ou a ausência de uma determinada propriedade não faz com que um texto deixe de pertencer a determinado gênero. Na visão de Marcuschi (2009), embora uma publicidade tenha o formato de um poema ou de uma lista de produtos em oferta, continua sendo uma publicidade, contanto que atinja seus objetivos. Da mesma forma, uma carta pessoal não deixa de pertencer ao gênero por não possuir a assinatura no final. Um artigo de opinião, publicado em um grande jornal pode ser estruturado em forma de poema e continuar sendo um artigo de opinião.

No entanto, não se deve confundir a intertextualidade inter-gêneros, que é a mescla de funções e forma de gêneros diversos em um dado gênero, e a heterogeneidade tipológica do gênero, caracterizada pelo fato de um gênero possuir várias sequências de tipos textuais, conforme já aludimos. 
O objetivo principal da mescla de gêneros é ocasionar no leitor/ouvinte ao mesmo tempo um processo de estranheza e reconhecimento. O primeiro em relação à forma e o segundo em relação à função. Porém, caso não haja reconhecimento por parte do interlocutor dos gêneros hibridizados, é possível que não haja a consecução dos objetivos pretendidos pelo autor do texto.

\section{Procedimentos metodológicos}

Busca-se estabelecer uma análise comparativa entre duas reportagens da revista semanal Época, da Editora Globo, publicadas nos dias 4 e 18 de agosto de 2008, números 533 e 535, respectivamente. As reportagens fazem parte da seção intitulada Saúde \& Bem Estar. A revista é publicada semanalmente com uma tiragem de aproximadamente 420 mil exemplares, distribuídos por todo o país.

A primeira reportagem, intitulada $O$ drama do transplante de órgãos, é de autoria da repórter Isabel Clemente. A segunda reportagem é de autoria da repórter e escritora Eliane Brum e apresenta o título A enfermaria entre a vida e a morte.

Por meio do confronto dos elementos linguísticos e estruturais dos dois textos, apresentar-se-á as características que ora os aproximam e ora os distanciam. Para tanto, recorreremos às considerações sobre a perspectiva sócio-interativa (MARCUSCHI, 2008), evidenciadas no capítulo anterior.

Serão observadas, dentre outras características, o público-alvo, as imagens (fotos), as legendas, as referências utilizados pelas autoras, a presença/ausência de figuras de linguagem (metáforas, metonímias, eufemismos etc), algumas estruturas típicas do texto, a subjetividade ou objetividade do conteúdo veiculado e as intertextualidades presentes nos textos.

\section{Análise}

Grandes semelhanças são observadas nos textos devido a serem publicados no mesmo suporte de gênero, a Revista Época, e, ainda, na mesma seção, Saúde \& Bem Estar. Além disso, foram produzidos com a consideração de um leitor inserido em um mesmo contexto social, cultural e histórico, já que são destinados a um público semelhante e contemporâneo. Outra característica que os assemelha é o fato de tratarem de temas muito próximos: as atuais condições em que se encontra a saúde no país, com ênfase em pacientes internados em hospitais públicos.

Diante de todas essas equidades entre os textos, é possível questionar se haveria então alguma diferença entre as reportagens. Para Chaparro apud Bonini (2003, p. 215), em um texto de reportagem não há um posicionamento direto do autor em relação aos fatos, mas o resultado de uma inspiração e da criatividade de quem escreve, "no aproveitamento literário de detalhes, para seduzir leitores ou acentuar a atribuição de significados aos fatos”. Há, então, um sujeito responsável pela transmissão de uma ideologia particular, que é construída com estratégias próprias.

Ao travarmos contato com os textos, é possível perceber que possuem abordagens diferentes em torno de temas semelhantes. Uma observação superficial já aponta essa disparidade.

O primeiro texto ( $O$ drama do transplante de órgãos) trata do problema dos transplantes no Brasil, denunciando a má gestão dos recursos, o desperdício e as tragédias pessoais em hospitais avançados de medicina. As fotos exibidas em toda a reportagem são coloridas, e os personagens são identificados e fotografados de frente, em poses simples, o que sugere uma reportagem centrada na objetividade.

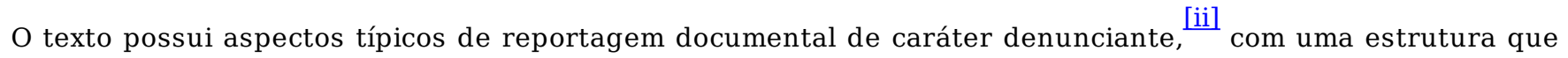
apresenta historicamente o tema tratado, bem como a posição atual do país em relação a esse tema, elementos usados para situar o leitor em relação ao que será apresentado nas páginas seguintes. Abaixo a reprodução do texto introdutório.

Uma das principais criações da medicina mundial nas últimas décadas, os transplantes são uma glória nacional desde 1968, quando o professor Euriclydes de Jesus Zerbini instalou um coração no peito de um boiadeiro internado no Hospital das Clínicas, em São Paulo - o que fez do Brasil o terceiro país do mundo a realizar uma cirurgia dessa natureza. Há vários anos o Hospital do Rim, em São Paulo, acumula a condição de mais ativa unidade de transplantes do mundo em sua especialidade. Pelo tamanho de sua população, o Brasil realiza um grande número de transplantes por ano - perto de 15 mil -, o que lhe permite, pela quantidade, ocupar um dos primeiros lugares do mundo na especialidade. Em termos relativos, a situação é menos animadora. A quantidade de cirurgias realizadas no país é incompatível com as necessidades da população. (p. 103)

A reportagem traz, ainda, inúmeras informações com dados estatísticos e probabilidades (inclusive com gráficos da quantidade de transplantes realizados no país), como se pode observar abaixo, por meio de trechos extraídos da reportagem:

Pelo tamanho de sua população, o Brasil realiza um grande número de transplantes por ano - perto de 15 mil -, o que lhe permite, pela quantidade, ocupar um dos primeiros lugares do mundo na especialidade. (p. 103) 
Estima-se que, todos os anos, seja realizada, no Brasil, apenas a metade do número de transplantes de córnea necessários. (p. 103)

Os transplantes de coração equivalem a menos de $5 \%$ do que seria preciso. As filas de espera crescem tanto que, dependendo do órgão, $10 \%$, às vezes até $30 \%$, dos pacientes, morrem antes de ir para a sala de cirurgia. (p. 103)

As filas de espera são imensas e não param de crescer. Chegam a 66 mil pessoas. (p. 104)

Nos Estados Unidos, a lista de pacientes em espera por um rim era de 14 mil pessoas em 1988. Passou para 63 mil em 2004. O número de doadores possíveis, no mesmo período, cresceu de 3.800 para 6.700 . (p. 104)

Além de farta informação quantitativa, há a preocupação com a exposição dos dados da evolução histórica dos transplantes no Brasil, o que atribui também à produção textual um caráter científico, com a busca de respaldo em dados reais a respeito do tema e em autoridades da saúde pública, especialistas no assunto em pauta, como se pode observar, por exemplo, no seguinte excerto (destaque nosso):

Em 2005, o professor Valter Duro Garcia, coordenador de transplantes da Santa Casa de Porto Alegre e uma das grandes autoridades do país no assunto, fez um estudo meticuloso sobre a situação. A partir de dados demográficos nacionais, ele concluiu que todos os anos o país produz entre 11 e 18 mil doadores de órgãos em potencial... (p. 104)

Os exemplos reais de transplantados ou de pacientes na fila do transplante não fazem parte do ponto central da reportagem, somente servem para ilustrar o tema central que gira em torno do drama do transplante de órgãos. É possível notar, na foto que ilustra a primeira página, a tentativa de identificar o paciente da fila de espera apenas com um número, com a inscrição "número de espera 534", com etiquetas de senha semelhantes às utilizadas em filas de espera de instituições públicas e privadas de serviços. Não há um rosto, o foco centra-se na mão que segura a etiqueta.

As páginas seguintes da reportagem trazem gráficos que exibem o aumento gradativo do número de pessoas que aguardam órgãos para transplante. No centro de cada página, fotos posadas exibindo o rosto dos personagens que necessitaram ou necessitam de transplantes de órgãos. Na última página, a cronologia dos transplantes de órgãos no mundo se encerra com o rosto da francesa Isabelle Dinoire, a primeira mulher a receber um transplante parcial de face em 2005.

Tratando particularmente dos elementos linguísticos empregados, constata-se o uso de uma linguagem jornalística investigativa, uma linguagem que privilegia a informação, sem a preocupação com seleção de elementos linguísticos literários e sem a opção pelo uso de figuras de linguagem, como metáforas e metonímias. Não há o uso de muitos termos técnicos ou científicos, prima-se pela simplicidade.

Em meio ao texto, há um personagem que já recebeu um transplante de órgão e obteve sucesso, um personagem que aguarda pelo transplantes de órgãos e um personagem que faleceu antes de receber o transplante. Exemplos de cada um dos possíveis destinos de quem aguarda na fila de transplante de órgãos.

É possível notar, em todo o texto, a preocupação com a vida, a necessidade da preservação da vida. É latente que o interesse central da reportagem é a busca incessante pelo prolongamento da vida.

Ao analisarmos o segundo texto (A enfermaria entre a vida e a morte), é possível, desde a página inicial, notar a primeira diferença entre as reportagens. Uma sequência de duas fotos em preto-e-branco, apresentam a morte do senhor Antônio Walter Correa. Na primeira foto, o personagem sorri, na segunda, uma mão fecha os olhos do homem já sem vida. Há um contraste entre as fotos que apresentam um rosto coberto de rugas, de alguém que se encontra na iminência da morte, e a relatada alegria do paciente, enfatizada na reportagem. A contradição aparente se faz presente também no cabeçalho, em que se lê em vermelho e preto, o título da coluna e o tema da reportagem:

\section{SAUDE E BEM-ESTAR MORTH}

As fotos exibidas em toda a reportagem são em preto-e-branco. A maioria das imagens retrata pessoas sorrindo, contrariando a impressão vigente no mundo ocidental que o encontro com a morte pode causar. A legenda de algumas fotos confirma a alegria: "João risonho", "João falante".

Não há, como na reportagem anterior, a introdução ao tema. O texto se inicia com uma narrativa centrada no personagem João Barbosa de Lima. Após o desfecho da narrativa, alude-se ao local da reportagem (A Enfermaria de Cuidados Paliativos do Hospital do Servidor Público Estadual de São Paulo) e ao tema central. Não há uma estruturação próxima a de uma reportagem documental ou denunciante, mas sim, em dados momentos, a estruturação de uma reportagem-conto ou de uma reportagem-crônica. ${ }^{[i i i]}$ Em caixa alta, anuncia-se um conteúdo permeado de figuras de linguagem que se estendem por todo o texto, como vemos abaixo: 
A divisão do texto em seções é característica comum dos dois textos pesquisados, contudo, diferentemente do texto anterior, em que se exibiam informações e dados estatísticos, bem como a opinião de especialistas a respeito do tema, no segundo texto os "capítulos" trazem histórias reais do cotidiano das pessoas internadas no Hospital do Servidor Público de São Paulo, sejam elas pacientes ou mesmo funcionários. A comprovação científica evidenciada no primeiro texto dá lugar à experiência pessoal e sentimentos em relação a tudo que os envolve.

Por vezes, há o uso da primeira pessoa do plural, em detrimento da impessoalidade da terceira pessoa do singular, como vemos no trecho seguinte, que traz inclusive a opinião do fotógrafo responsável pelas imagens que acompanham o texto:

Para fazer esta reportagem, acompanhamos a rotina da Enfermaria nessas sextas-feiras. E os últimos 115 dias de uma paciente. O fotógrafo Marcelo Min, que se dedica a fotografar partos, logo constatou: "Nascer e morrer é a mesma coisa". (p. 58)

Diferentemente da reportagem sobre os transplantes, de Isabel Clemente, os personagens não são meros elementos que ilustram o problema central do texto. Eles são os elementos essenciais da reportagem, acompanhados durante dias, alguns, até a morte.

Se no texto anterior a luta dos personagens era pela vida e a simples dúvida em relação ao sucesso no transplante era causa de preocupação, no presente texto, o autor busca demonstrar que a certeza da morte não aflige os pacientes, pelo contrário, todos os personagens retratados demonstram conformação e felicidade.

No texto, não há a presença de dados estatísticos, apenas de extensos trechos ora narrativos, ora argumentativos, entremeados por depoimentos pessoais dos personagens. Não se trata de uma narrativa objetiva, investigativa, mas de uma narrativa entremeadas de ricas descrições com elementos linguísticos diferenciados e figuras de linguagem. Vejamos abaixo:

De repente João Barbosa de Lima começou a rir às gargalhadas. Seu corpo devastado pelo câncer se sacudia todo na cama de hospital. Depois de meses sem um sorriso, o iceberg que comprimia seu riso se desprendia dele.

Puxava um lenço encarnado para enxugar os olhos.

João sabia que morreria, mas tinha descoberto também o que o fazia viver. A família ao redor, esse riso à toa, a mulher de uma vida, a vida vivida.

$\mathrm{O}$ grande embate travado naquele que, desde o século $\mathrm{XX}$, é o altar da morte - o hospital - e pelos seus sacerdotes modernos - os médicos - trata dos limites de prática médica diante do fim da vida. (p. 58)

A legenda das fotos iniciais prenuncia a visão proposta pelo autor, que trata de maneira eufemística a morte de um de seus personagens.

VIVENDO A MORTE Antônio Walter Correia abriu o sorriso da primeira foto antes de começar a contar uma das muitas histórias de sua vida. Na segunda foto, três dias depois, o contador de histórias encerrou a sua suavemente (p. 57)

As referências utilizadas pela autora do texto diferem das referências do primeiro texto. Aqui, são privilegiados textos de humanistas, como historiadores e antropólogos. Vejamos:

O historiador francês Philippe Áries escreveu sobre o tema... "A morte no hospital, eriçado de tubos, está prestes a se tornar hoje uma imagem popular mais terrífica que o trespassado ou o esqueleto das retóricas macabras" (p. 59)

Começamos a morrer no exato instante em que começamos a viver. E hoje estamos mais mortos do que estávamos ontem. Mas, atualmente, mais que em qualquer outro período histórico, vivemos a morte como uma experiência marginal. (p. 59)

"Hoje a morte e o luto são tratados com o mesmo pudor que os impulsos sexuais há um século", escreveu o antropólogo britânico Geoffrey Gorer, em 1955, em Pornografia da Morte. (p. 59)

Cada leito é uma janela para o mundo de alguém. Perto da morte, a vida fica mais nua. E as contradições se explicitam. Morre-se como se vive, só que de modo mais radical. Reduzido ao essencial, um paciente tinha uma força que ninguém sabia explicar. Ergueu-se sobre si mesmo, levantou um braço esquálido e, sem poder falar, disse chega. O câncer tinha lhe roubado as cordas vocais, mas não conseguira lhe arrancar a raiva. Ele morreu sem um som, mas com fúria. Estava nu. Exceto por um detalhe. No dedo um anel de doutor. Por toda a vida ele havia sido pedreiro. A presença do anel, mais do que a falta das roupas, era o que o deixava mais nu. (p. 59)

A escolha de um gênero híbrido (reportagem-conto/reportagem-crônica) ou de um subgênero do gênero reportagem pelo autor pode ser justificada pela tentativa de evidenciar uma visão pouco convencional da morte, compartilhada na ala de cuidados paliativos do Hospital do Servidor Público. A objetividade e rigidez do gênero reportagem documental (primeiro texto) possivelmente não conferiria ao texto as mesmas qualidades e certamente não despertaria no leitor os mesmos interesses e sentimentos.

Ainda que as produções textuais estejam em um mesmo veículo (suporte/hipertexto), as organizações retóricas 
são diferentes e também o é o propósito comunicativo das autoras. A argumentação do primeiro texto gira em torno da exibição de dados, sejam eles estatísticos ou mesmo fundamentados por especialistas. No segundo texto, a apelação fica por conta das impressões da autora e também do possível leitor.

A influência social e contextual exercida sobre o autor do texto é outro fator que pode ter influenciado na produção de um discurso subjetivo e com grande índice de autoria, visto ter havido grande envolvimento entre os personagens e o produtor do texto.

\section{Considerações finais}

Como observado, ainda que os gêneros possam ser constituídos cultural e historicamente, não devem ser considerados como modelos estruturais ou categorias estanques, a serem seguidas. Na verdade, o gênero serve somente para nortear a produção textual. Serve como modelo a ser seguido, mas também subvertido. Vejamos, no quadro abaixo, as características estruturais de cada texto analisado:

\begin{tabular}{|c|c|c|}
\hline critérios analisados & $\begin{array}{l}\text { O drama do transplante de } \\
\text { órgãos }\end{array}$ & $\begin{array}{l}\text { A enfermaria entre a vida } e \\
\text { a morte }\end{array}$ \\
\hline suporte & revista & revista \\
\hline público & classes A e B (C) & classes A e B (C) \\
\hline data da publicação & agosto de 2008 & agosto de 2008 \\
\hline seção da publicação & Saúde e Bem-estar & Saúde e Bem-estar \\
\hline imagens & $\begin{array}{l}\text { coloridas } \\
\text { ângulo convencional (foto do } \\
\text { personagem de frente, posadas) }\end{array}$ & $\begin{array}{l}\text { preto-e-brancas } \\
\text { ângulo não-convencional (fotos } \\
\text { expontâneas) }\end{array}$ \\
\hline legendas & mais objetivas & mais subjetivas \\
\hline gráficos e índices & presentes em todo o texto & ausentes em quase todo o texto \\
\hline $\begin{array}{l}\text { opinião de especialistas } \\
\text { (comprovação científica) }\end{array}$ & presentes em todo o texto & ausentes em quase todo o texto \\
\hline $\begin{array}{l}\text { figuras } \\
\text { (metáforas, linguagem } \\
\text { eufemismos) }\end{array}$ & ausentes & presentes \\
\hline estrutura & $\begin{array}{lll}\begin{array}{l}\text { reportagem } \\
\text { denunciante }\end{array} & \text { documental ou } \\
\end{array}$ & $\begin{array}{l}\text { reportagem-conto } \\
\text { reportagem-crônica }\end{array}$ \\
\hline $\begin{array}{l}\text { aproximação do autor em } \\
\text { relação ao texto (índice de } \\
\text { autoria) }\end{array}$ & $\begin{array}{l}\text { pouco } \\
\text { caracterizado pelo } \\
\text { número de citações }\end{array}$ & $\begin{array}{lr}\text { fortemente } & \text { evidenciado, } \\
\text { caracterizado } & \text { pela } \\
\text { argumentação pessoal } & \\
\end{array}$ \\
\hline $\begin{array}{l}\text { o p i n i ã o subjetiva } r \\
\text { depoimentos pessoais } \\
\text { personagens envolvidos }\end{array}$ & pouco presentes & muito presentes \\
\hline intertextualidade & $\begin{array}{l}\text { predominantemente com textos } \\
\text { ci entífi c o s, jornalísticos e } \\
\text { opinião de especialistas }\end{array}$ & $\begin{array}{l}\text { predominantemente com textos } \\
\text { literários e impressões pessoais } \\
\text { dos personagens }\end{array}$ \\
\hline forma de argumentação & dados estatísticos & $\begin{array}{l}\text { impressões pessoais (autora e } \\
\text { personagens) }\end{array}$ \\
\hline
\end{tabular}

Quadro 1: Características presentes nos textos a nalisados

No primeiro texto, O drama do transplante de órgãos, é possível observar a estruturação de todo o texto em torno de um modelo de gênero que muito se aproxima do modelo mais usual do gênero reportagem jornalística em revista semanal, muito próximo do modelo também usado em reportagens jornalísticas em jornais diários. Histórica e culturalmente, a estrutura se assemelha muito à estrutura encontrada na maioria dos textos jornalísticos desse gênero.

O segundo texto, A enfermaria entre a vida e a morte, apresenta uma estruturação menos convencional para uma reportagem jornalística, ocasionada pelo uso de estruturas e elementos linguísticos pouco comuns nesse suporte. Essas estruturas e elementos linguísticos normalmente são utilizados em gêneros literários, como romances, novelas e contos. Contudo, como alude Marcuschi (2009), essa quebra da estrutura canônica não faz com que o texto deixe de ser uma reportagem jornalística. Tem-se, nesse caso, um texto híbrido com uma estrutura inter-gêneros, com a presença de características dos gêneros literários narrativos, como o conto, a novela e o romance, para compor um texto do gênero reportagem, o que é reforçado pelo suporte dessa produção textual, no caso a revista.

Ainda que o gênero textual sofra influência direta do meio em que é produzido, seja cultural ou historicamente, a presença da subjetividade do indivíduo produtor do texto é de extrema importância na elaboração textual, por vezes ocasionando dentro de um mesmo contexto, resultados diferenciados.

\section{Referências}

ADAM, J. M. Elements de Linguistique textuelle. Teorie e pratique de l' analise textuelle. Liérge: Mardaga, 1990.

BAZERMAN, C. Gênero, agência e escrita. São Paulo: Cortez, 2006a. Gêneros Textuais, tipificação e interação. São Paulo: Cortez, $2006 \mathrm{~b}$.

BEAUGRANDE, R. A. DRESSLER, W. U. Introduction to Text Linguistics. London: Longman, 1981.

BIBER, D. Variation Across Speech and Writing. Cambridge: Cambridge University Press, 1988.

BONINI, A. Os gêneros do jornal: o que aponta a literatura da área de comunicação no Brasil? Linguagem em (Dis)curso. Tubarão. v. 4, n. 1, p. 205 - 231, jul. /dez. 2003.

BRONCKART, J. P. Atividades de linguagem, textos e discursos: por um interacionismo sócio-discursivo. São Paulo: 
EDUC, 1999.

MARCUSCHI,

L. A. A questão do suporte dos gêneros

textuais.

2003.

Disponível

em: www.bbs.metalink.com.br/ lcoscarelli/GEsuporte.doc. acesso em 27/01/2009.

MARCUSCHI, L. A. Produção textual, análise de gêneros e compreensão. São Paulo: Parábola Editorial, 2008.

MARCUSCHI, L. A. Gêneros textuais: definição e funcionalidade. Disponível em: http://www.proead.unit.br/professor/linguaportuguesa/arquivos/textos/Generos_textuias_definicoes_funcionalidade.rtf .acesso em: 27/01/2009.

SWALES, J. M. Genre Analysis. English in Academic and Research Settings. Cambridge: Cambridge University Press, 1990.

[i] MARCUSCHI, L. A. Produção textual, análise de gêneros e compreensão. São Paulo: Parábola Editorial, 2008.

[ii] A reportagem documental apresenta os relatos de maneira objetiva, acompanhados de citações que complementam e esclarecem o assunto tratado. É expositiva e se aproxima da pesquisa. Algumas vezes possui caráter denunciante. Apóia-se em dados que lhe conferem fundamentação e dão cunho pedagógico. fonte: http://www.jorwiki.usp.br/gdmat07/index.php/Modelos de Reportagem.

[iii]

A reportagem-conto particulariza a ação, escolhendo um personagem para ilustrar o tema que pretende desenvolver. A reportagem-crônica se detém mais em situações fortuitas e flagrantes do cotidiano, conduzindo a narrativa de forma impressionista, por meio de um narrador colocado em posição observadora ou reflexiva. (fonte: http://www.jorwiki.usp.br/gdmat07/index.php/Modelos de_Reportagem). 